\title{
Uma Janela Indiscreta sobre o Tráfico de Drogas em Copacabana
}

\author{
JOÃO MARCELO EHLERT MAIA*
}

\author{
PEREIRA, Luiz Fernando Almeida. \\ De Olhos bem abertos: rede de tráfico em Copacabana. \\ Rio de Janeiro: FGV, 2003. \\ Prefácio: Alba Zaluar
}

Há muitas maneiras de trabalhar sociologicamente o tema das drogas na sociedade brasileira contemporânea. Em geral, a questão mais ampla do tráfico e de suas conexões com o fenômeno da violência urbana tende a englobar a discussão, o que produziu significativos estudos e mobilizou numerosos cientistas sociais. Pode-se falar que hoje, no Brasil, já há uma massa crítica voltada para essa área. Em outro registro, alguns trabalhos buscam entender o papel das drogas na sociabilidade juvenil, e suas relações com outras facetas dessa cultura. A dissertação de mestrado de Luiz Fernando Almeida Pereira, publicada em livro com o título De olhos bem abertos: rede de tráfico em Copacabana, não segue nenhum desses registros especificamente. O leitor que se aventurar por esse trabalho encontrará uma interessante pesquisa ancorada numa abordagem teórico-metodológica que nos leva para a "intimidade" da relação do consumidor com o mercado de drogas. Um texto que abre uma janela "indiscreta" sobre esse mercado e permite ao leitor entender melhor os mecanismos opacos que organizam uma atividade tão fugidia à observação casual.

O objetivo da pesquisa é claro: dissecar sociologicamente o mundo noturno dos consumidores de cocaína e o modo como esses personagens constroem relações fugazes e nervosas com os fornecedores do "asfalto" - os chamados "vapores". Ou seja, no lugar da favela, do armamento pesado e da criminalidade de alto impacto, Luiz Fernando prefere nos introduzir no universo "ilícito" de Copacabana - bairro escolhido como campo de observação -, o que dá novo colorido a um tema que ameaçava ficar cristalizado na armadura da conexão "tráfico-violência". Afinal, como ignorar essa vida nervosa que enreda inúmeros atores e ocupa posição central na dinâmica social de um dos bairros mais importantes da Zona Sul da cidade? Como entender esse fenômeno avassalador na sociedade contemporânea sem descer aos meandros de seu funcionamento "rotineiro", que se imiscui por todas as dobras de uma cidade complexa e multifacetada? 
Copacabana é o cenário e também o tema do primeiro capítulo da obra. Nele, Luiz Fernando procura decifrar o lugar ocupado pelo bairro na malha urbana carioca e nas representações dos usuários que o freqüentam em busca de cocaína. É essa segunda dimensão que ganha força ao longo da seção, o que permite ao autor mostrar qual o repertório de imagens que dá sentido a essa busca. No caso, sobressai a figura do "jardim do pecado", local dotado de um amplo espectro de prazeres, diversões e oportunidades de pequenas aventuras urbanas, combinado a um certo cosmopolitismo que permite a todos escaparem das movediças fronteiras morais que reprimem os "comportamentos desviantes". Contudo, o autor procura não reduzir uma dinâmica urbana rica a uma suposta área livre de convenções, como se Copacabana fosse, apenas, uma área voltada para as lícitas ou ilícitas diversões urbanas. Nesse registro, Luiz Fernando mostra que as redes de tráfico que operam no asfalto do bairro se enredam num cenário tido como "normal", não-estigmatizado ou marcado como área "proibida". Esse cruzamento de fronteiras permite a esse universo relacional uma certa "leveza", se comparado à dinâmica que organiza a venda e consumo de drogas nos morros do Rio de Janeiro.

Essa leveza é um dos assuntos que organizam o capítulo dois. Afinal, "leves" são os "vapores" que somem e aparecem de forma rápida, e que cruzam as ruas do bairro como nômades noturnos eternamente disponíveis. Sem identidades fixas, muitas vezes conhecidos apenas por apelidos ou nomes falsos, esses personagens só se comunicam com frases rápidas, códigos e gírias. De acordo com Luiz Fernando, não há lugar para formalidades e sólidas relações entre usuários e vendedores, dado que a confiança necessária para o funcionamento dos "negócios" exige de todos vigilância e prontidão. Afinal, muitas vezes os vapores se deslocam com dinheiro e só entregam a mercadoria em outro momento e lugar. Difícil tarefa a do pesquisador, obrigado a seguir pistas discretas e a treinar de forma aguda seu olhar "etnográfico". Esse jogo, cuja peça principal é a "confiança", é o nexo que dá sentido ao livro e às inquietações sociológicas do autor. Afinal, como compreender a construção de relações com algum grau de estabilidade num universo tão instável? Que espécie de "confiança" pode organizar uma relação que se passa num universo ilegal e sempre sujeito ao devassamento produzido pelos agentes da lei?

A dimensão "perigosa" desse universo é decifrada por Luiz Fernando no terceiro capítulo, no qual dialoga com outros atores dedicados ao tema das drogas. Nesse registro, o autor busca caracterizar o perfil do tráfico nas ruas de Copacabana e o impacto dessa configuração nas relações entre usuários e 
vapores. Se a ostensiva presença armada de traficantes inexiste no bairro, a constante vigilância policial exige de todos os envolvidos certa discrição que produz uma série de efeitos sobre a atividade. Como mostra o autor, os usuários "pesados", que não se "controlam" e agem de forma irresponsável, são malvistos e excluídos das tênues redes que organizam o mercado. Ao mesmo tempo, o alto preço da droga vendida fora dos morros obriga os consumidores a uma certa "racionalização" da conduta, que permita o aproveitamento mais "seguro" dos recursos financeiros empregados e da própria mercadoria adquirida. Nesse ponto, Luiz Fernando mostra como a visão corrente de um consumidor de drogas "descontrolado" e movido por uma paixão compulsiva e doentia não encontra eco na realidade observada, repleta de personagens que rejeitam o estereótipo e organizam suas condutas por uma certa moderação que permite um trânsito mais "tranqüilo" pela noite de Copacabana.

Mas é no capítulo quatro que está o centro da argumentação do livro. Nele, Luiz Fernando mobiliza autores como Georg Simmel e Norbert Elias, para construir um quadro teórico que lhe permite situar o objeto no âmbito da Sociologia. Nessa chave, o autor mostra como esse universo é marcadamente "interacional" e só pode ser desvendado com recurso à própria lógica que organiza o frágil jogo entre consumidores e vendedores, que se enredariam numa teia de "interdependência". Ou seja, não caberiam, portanto, explicações macrossociológicas que reduzam a especificidade e "leveza" dessas relações a forças impessoais que supostamente atribuiriam comportamentos e atitudes. Fiel a esse legado teórico, Luiz Fernando elege a "confiança" como categoria central e mostra como ela é erguida em bases frágeis, estando sujeita a uma constante negociação. Olhares, códigos lingüísticos e gestos rápidos seriam os elementos básicos nessa movimentação que demandaria um mínimo de comprometimento mútuo entre os atores envolvidos. Trata-se de um "mercado", é certo, mas de contornos traiçoeiros, o que transforma o momento da transação num ato "carregado" e tenso.

Se as rotineiras trocas capitalistas são cumpridas com um mínimo de envolvimento e obedecem apenas aos ditames do impessoal mecanismo do contrato, essa troca específica requer uma certa habilidade. $\mathrm{O}$ autor busca captar a dinâmica desse delicado universo de forma expressiva, conectando as "miudezas" do jogo movido pela "confiança" aos problemas levantados pela teoria social. Decerto que essa articulação é complexa e nem sempre bem resolvida no texto - como comparar esse "mercado" a outras formas de transação, utilizando as categorias "simmelianas" de "confiança" e "segredo"? 
- , mas o esforço do autor sugere que há um campo a ser explorado. Afinal, não se trata apenas de desvendar as relações entre usuários de drogas e vendedores no varejo, mas de entender uma determinada mecânica sociológica, própria de relações instáveis e que ocorrem nas "margens" da sociedade.

Nas menos de cem páginas que marcam as fronteiras do texto, há bons indícios para uma sociologia das interações produzidas pela venda de drogas no Rio de Janeiro, e que certamente serão seguidos pelo autor na sua trajetória intelectual. Ainda há muito que decifrar sobre a dinâmica dessas transações, e sobre o tipo de mercado constituído pela venda de drogas. Decerto que certas pistas poderiam ser mais bem exploradas, o que incrementaria a aventura teórica proposta.

O capítulo sobre Copacabana, por exemplo, poderia dialogar com uma produção historiográfica que situasse a dinâmica urbana da cidade e suas associações com outras atividades "ilícitas", o que permitira um enquadramento mais bem acabado sobre esse traço tão marcante do Rio de Janeiro. Esse diálogo auxiliaria o autor no enfrentamento de uma questão suscitada pela leitura de seu livro: como comparar esse "mercado" com outras transações ilícitas e rotineiras que se entranham no cotidiano da vida carioca? Ademais, o próprio encadeamento do texto ganharia mais vivacidade, com uma maior problematização do "cenário". Um enfoque comparativo mais delineado que opusesse as redes de tráfico no asfalto e nos morros também realçaria o ponto trabalhado pelo autor sobre a instável dinâmica da "confiança", o que tornaria seu argumento mais sólido. Aliás, um retrato mais preciso dos "vapores" e de suas formas de atuação permitiria uma composição mais completa do objeto, o que auxiliaria na articulação entre etnografia e teoria social, sugerida no capítulo quatro.

De modo semelhante, o capítulo sobre as formas de comunicação entre usuários e vendedores poderia explorar os códigos lingüísticos e gírias, já que a interação é o foco principal da pesquisa. Como, afinal, esses personagens se comunicam? Essas eventuais lacunas são constitutivas de todo trabalho em Ciências Sociais, e terminam por configurar os futuros caminhos de pesquisa. Caminhos estes que poderão ser trilhados por Luiz Fernando e que incorporarão ao repertório da Sociologia contemporânea outras "janelas indiscretas" sobre temas tão difíceis e urgentes.

\section{NOTA}

Doutorando em Sociologia pelo Instituto Universitário de Pesquisas do Rio de Janeiro. Endereço eletrônico: jmehlert1 @ hotmail.com. 